both in Seattle. It will test an intranasal insulin spray against placebo in people with mild cognitive impairment or early Alzheimer's. Insulin receptors are abundant in synapses in brain regions that are important for memory and cognition, and in Alzheimer's, amyloid- $\beta$ can knock out the receptors and disrupt memory formation. Flooding rat brain cells with insulin has been found to block the fragments and protect the receptors (F. G. De Felice et al. Proc. Natl Acad. Sci. USA 106, 1971-1976; 2009). When Craft tried the strategy in humans by giving intranasal insulin to people with mild cognitive impairment or early Alzheimer's, the results were impressive: about three-quarters remained stable or improved cognitively over the four months of treatment, Craft says.

\section{PLAN FOR THE FUTURE}

Craft says that she was "thrilled" to be funded for a larger, follow-on trial. But like many in the field, she worries that the national Alzheimer's plan is under-funded in the long term. "We all would like to believe that this is an important moment," she says, "but we need to see follow-up in order to be truly convinced that this will provide an ongoing, coherent effort to address Alzheimer's disease."

On 15 May, an advisory council to the US Department of Health and Human Services recommended that the government quickly ramp up research spending to $\$ 2$ billion per year if it wants to meet its goal of developing effective treatments and preventive measures by 2025 . That would mean a quadrupling of the NIH's current spending on Alzheimer's research.

"We really have all the pieces we need to move forward in the development of effective therapeutics," says Paul Aisen, a neuroscientist at the University of California, San Diego, and director of the Alzheimer's Disease Cooperative Study - a 21-yearold programme of government-funded clinical studies aimed at developing Alzheimer's treatments. "The missing piece right now is the money."

The first test of a follow-up will come later this year as Congress wrestles over the administration's 2013 budget request for the NIH. Included in the request is an additional $\$ 80$ million for Alzheimer's research. Proponents say that a failure to adequately fund research today will only lead to higher costs later.

"We're in trouble now," says Aisen, "but in another 20 years, if things don't change, we're going to be in a dreadful situation." -

\title{
Global council aims to coordinate science
}

\section{Research-agency heads from around the world agree to formulate shared principles to aid collaborations.}

\section{BY RICHARD VAN NOORDEN}

$I^{n}$ nternational research collaborations are multiplying fast, with one-quarter of the world's science and engineering publications now featuring authors from more than one country. But not all national funding agencies manage their science in the same way - researchers in China win grant funding through very different processes from their European peers, for example - which can hamper projects that span borders.

To tackle the problem, a voluntary forum, the Global Research Council (GRC), has been formed to share best practice and encourage common principles. Last week, the leaders of about 50 national research-funding agencies met at the headquarters of the US National Science Foundation (NSF) in Arlington, Virginia, to discuss the GRC's agenda: issues such as peer review, data sharing, research integrity, open access, career development and ethical conduct in research on humans. As the largest-ever gathering of research agencies, it was a "historic moment", says Suzanne Fortier, president of Canada's Natural Sciences and Engineering Research Council.

NSF director Subra Suresh, who coordinated the meeting, hopes that the GRC will broker international collaborations and co-funding arrangements to boost the globalization of science (see 'Global science'). From now on, says Glaucius Oliva, president of Brazil's National Council for Scientific and Technological Development, agencies will get together much more frequently - with at least one meeting in each of five world regions before each annual global meeting of the GRC - and will send more staff members on exchange visits abroad.

Organizing the forum was certainly an impressive feat, but it isn't yet clear how the GRC might develop. "The key thing is that this shouldn't become a big, expensive, international science talking shop," says Kieron Flanagan, who studies science and technology policy at the University of Manchester, UK.

The GRC's first meeting produced a set of short, uncontroversial statements on common principles for peer review to assess the merit of proposed scientific projects. The principles include transparency, integrity, impartiality and confidentiality, but are not legally binding,

\section{GLOBAL SCIENCE}

The proportion of research papers from international collaborations is increasing in many regions.

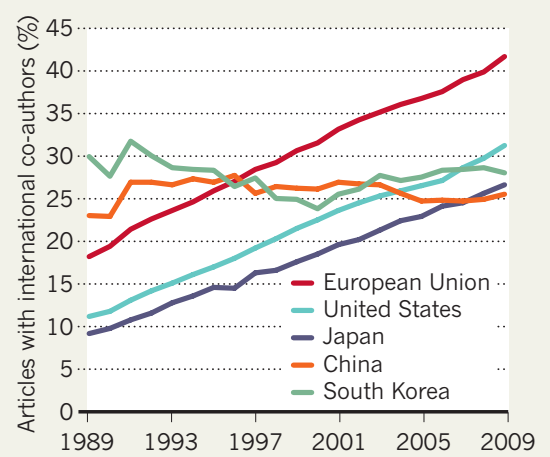

serving only as common aspirations. "If the statements stay at this general level they're not going to be Earth-shattering," says Flanagan.

But behind the scenes, agency heads were sharing tips and experience. Oliva, for example, says that his agency is coming under government pressure to focus on practical problems, and is rethinking its evaluation systems to include indicators that value innovation. "It's nice to see how other countries are dealing with these indicators," he says.

Before the next major GRC meeting - in Berlin in 2013, by which time the council is expected to have almost 100 members - the group will discuss research integrity and open access to scientific data and published research. The basic principles of research integrity have already been laid down in international guidelines such as the Singapore Statement, agreed by researchers and funders in 2010. But Matthias Kleiner, who heads the DFG, Germany's main research-funding agency, says that the GRC could discuss practical questions such as how to tackle the problem of researchers being sanctioned for misconduct in one country, but continuing their research freely elsewhere.

Agreeing on principles for open access will be much tougher, says Kleiner. But it is such an
ONATURE.COM Read more at Nature's metrics special: www.nature.com/metrics important issue, he adds, that "only in a global collaboration could we come to really reliable, practical, sustainable, solutions". - 